\title{
Livelihood Opportunities Through Sericulture a Model of Gharghoda Tribal Block, Raigarh Dist
}

\author{
S.K. Dewangan \\ Department of Zoology, Faculty of Life Science, \\ Central Gurughasidas University Bilaspur Chhattisgarh, India
}

Received 2013-06-18, Revised 2013-08-17; Accepted 2013-08-20

\begin{abstract}
Livelihood generation is one of the major potentials of sericulture and silk industry. Sericulture has emerged as the most important cash crop with minimum investment, low gestation period, high employment potential and highly remunerative return. It is well suited to the agrarian economy of the Tribal. Suitable for every section of society, a big farmer or a landless, aged person or a youth, man or a woman. Involves simple technology, which is easy to understand and adopt. Sericulture has provided downstream employment and income generation in rural and semi-urban areas, high participation for low-income and socially under privileged groups. This study investigate that how sericulture fulfill the opportunities of livelihood for tribal. The study finds that-Sericulture is the activity of low investment and high output. The study concludes with some suggestions to improve the long term feasibility of sericulture.
\end{abstract}

Keywords: Sericulture, Employment, Tribal, Income, Tasar

\section{INTRODUCTION}

In India, agriculture and agro-based industries play a vital role in the improvement of the rural economy. Limited availability of land, limited cash returns and agriculture being confined to one or two seasons in the year have made villages to look for supporting rural industries such as sericulture (Rai, 2006). The word "Sericulture" has been derived from the word "Su" ( $\mathrm{Si})$ which means silk. Sericulture is basically an agroindustry. It is divided in two sectors namely farm and industry (Shrivastav, 2005). Sericulture broadly comprises inter-linked activities such as food plant cultivation, maintenance to feed the silkworms, silkworm rearing to produce the silk cocoons, reeling the cocoons for unwinding the silk filament, yarn making, weaving and processing of fabric (Ahmed and Rajan, 2011). There are 10 million silkworm rearers and 0.5 million related industrial workers in the world (Seidavi et al., 2005). Asia is the top producer of silk in the world contributing $95 \%$ of the total global output. There are 58 countries on the world map of silk; bulk of it is produced in China and India, followed by Japan, Brazil and Korea (Nagaraju, 2008). Sericulture in India is a fairly organized activity and is largely rural based and labor intensive. Cultivation is spread over 22 States, covering 172000 hect. Across 54000 villages operating 258000 handlooms and 29340 power looms (Dewangan et al., 2011a) Sericulture play very effective role in the utilization of the natural resources in a most effective manner for socio-economic upliftment with livelihood, employment and income generation (Malik et al., 2008) Sericulture is a potential sector of the agriculture to raise economic status of the farming community and also earning foreign revenue (Thapa and Shrestha, 1999). Sericulture is an integral part of tribal life, practiced by about 1.5 lakh tribal populace in the states of Jharkhand, Chhattisgarh, Orissa, Madhya Pradesh, Utter Pradesh, West Bengal, Bihar, Maharashtra and Andhra Pradesh (Shetty et al., 2007).

Presently in Chhattisgarh three types of silk viz. Mulberry, Tasar and Eri are produced; Where Tropical Tasar and mulberry are reared on commercial scale (Rakesh, 2008). Tasar is commonly named as Kosa. 
Sericulture is being practiced by the tribal of traditional Districts of Baster, Raigarh, Bilaspur and Surguja (Chatterjee and Chakravorty, 2009). There are 258 wellrecognized tribal communities, notified as scheduled tribes in India (Sinha, 2003). This culture is able to generate quite remunerative and meaningful employment (Jolly, 1967; Narsimha, 2003). Tasar sericulture is a labor intensive industry in all its phase. It can generate employment up to 11 persons for every $\mathrm{kg}$ of raw silk produced (Ramalaxmi, 2007).

Fairly good numbers of references are on record about livelihood opportunities and employment generation.Tropical tasar sericulture is the rearing of wild silkworms for production of tasar silk and it provides livelihood to tribal's in India (Suryanarayana and Shrivastava, 2005). During 1977-78 the persons employed in sericulture were only 38.06 lakh (Hanumappa, 1993). During the year 1990-91 About 60, lakh people employed in sericulture activities in country (Singhvi et al., 1996). In the year 2010-11 the employment in sericulture sector was 72.5 lakh persons (i.e., 52.20 lakh farmers, 3.70 lakh reelers and 16.60 lakh weavers) when compared to 68.17 lakh persons during 2009-10 (Ganie et al., 2012). Sericulture is the only cash crop, which provides frequent and attractive returns in the tropical states of the country through year. The average annual income per hac. Was around Rs. 40,000 (Jagannathan, 1995). In Sundergarh district [Orissa], on an ave. a rearer's family reares $350 \mathrm{dfl}$. annually and contributes total annual income of Rs. 44500/(Brahmachari, 2004) Socio-economic condition of the tasar rearers/reelers/weavers in Korba district (Chhattisgarh) from tasar silkworm rearing, formed about $19 \%$ of the total income Rs. 47631 (Brahmachari, 2006). The net return/acre/year from sericulture was worked out to Rs. 43933 for the large scale farmers and Rs. 41741 for small farmers in Karnataka and Rs. 50422/acre/year and Rs. 41154/acre/year respectively in Tamil Nadu (Kumaresan and Devi, 2007). Sericulture has been found to be one of the important economic enterprises. An average net income of Rs. 67296 /hac./year through sericulture area (Dandin, 2008).

Sericulture is the activity of low investment and high output (Benchamin and Jolly, 1987). The tasar silkworm is a boon to its rural tribal rearers as their livelihood linked with the collection and sale of nature grown tasar cocoons (Nayak, 2000; Hansda et al., 2008; Ojha et al., 2009) Sericulture is a cottage, agro-forestry and forestry based industry that provides sustainable livelihood to several rural communities in the country to earn foreign exchange (Chatterjee et al., 2007) Silk industry has lot of socio-cultural and traditional linkages in India and plays a vital role on rural economy and hence, the aboriginals are practicing sericulture simultaneously with agriculture for base livelihood (Thangavelu, 2002; Mahapatra, 2009).

\subsection{Aims and Objectives}

The Studies is concentrated at the Gharghoda block of Raigarh district. This will include Identification of the areas where the tribal populations have been directed to adopt sericulture practices for their livelihood. Since how long this population is practicing sericulture. What percentage of male, female are involved in this process?

\section{MATERIALS AND METHODS}

Gharghoda Block of Raigarh district, Chhattisgarh state, was purposely selected for the study, based on potentiality and production of tasar/mulberry cocoons, where both types of sericulture-mulberry and tasar are being practiced. The study area has about 364 acres under mulberry cultivation though effective area is only 80-120 acres. Mulberry gardens are 18 and Reeling Unit in 1 number.

Tasar culture is a traditional and exclusive craft of the tribal of study area and is being practiced since10 years. Total area covered under tasar centers is about 3153.25 acres though effective area is about 2350 acre. Tasar centers are 22 in number. Tasar plantation under CGSP is situated in 57 sites and covers 3795 acres. Tasar rearings in forest are covered 4729.88 acres. The total beneficiaries are 5739 out of them 3347 are tribal in the district (DG, 2004).

Initially the list of sericulture villages and the names of beneficiaries were obtained from local sericulture department of Gharghoda Block, The primary data was collected from the sampled respondents following the personal interview method using structured interview schedule standardized.

In the above mention block four villages were selected at random and in each village 25 beneficiaries were selected at random for collection of data. Thus 100 beneficiaries were selected from block. The farmers were post classified into main and additional based on the engagement of employment.

The information sought from the respondents involved in sericulture activities consisted of three types. The first type pertained to general information. The second type was related to Occupational Status, Employment days in a year, Total Monthly Income, 
Total Expenditure, Occupation before the Sericulture, Duration of Sericulture Work, Main Occupation related to Sericulture, Average Annual Income from the Old Occupation, Crops take in a year, Cocoon produced in each crop, Profit from each crop, Yearly production of cocoons, Average Annual Income. The third type of information pertained to the Losses in Sericulture, Compensation by Government, Loan according to requirement, Attachment with Sericulture, Sericulture is favorable or not, Traditional Business is affected or not, Total labor period, Change in economic status, Change in Annual Income through Sericulture, Displacement by Sericulture, Impact of Sericulture in Life Style and economics of silk production.

Primary and secondary data was analyzed using various statistical tools viz., mean, mode and median.

\section{RESULTS AND DISCUSSION}

\subsection{Employment from Sericulture}

In the study area only 1 beneficiary out of 100 adopted the sericulture as main occupation and rest 99 as secondary. The number of working member in 8 families is only 01 and the same way in 41 families is 02 , In 21 families is 03 , in 18 families 04 and in 12 families 05 (Dewangan et al., 2011b).

\subsection{Man Days in a Year}

Out of 100 samples in study area $13 \%$ received employment for duration of 100-150 days and 63\% for 151-200 days and 23\% of 201-300 and 1\% for more than 300 days.

\subsection{Average Monthly Income}

The total monthly income obtained from all sources to the families involved in sericulture occupation is average 3670/-. The respondent tribe of study area collects forest minor products and thus they earn income about 5800/- once in year.

The total monthly expenditure from all sources to the families is about 2665/-. Only 09 respondents are in debt. Prior to starting sericulture occupation well over $3 \%$ of the total people were involved in agriculture and $83 \%$ in agricultural labor. Only $14 \%$ are reported rearing silkworm and agriculture simultaneously. Now 104 men and 97 women are involved in this silkworm rearing, agriculture and silkworm rearing, plantation and silkworm rearing and labor.

Before having sericulture occupation, the economic condition of all respondent was bad. This occupation is not new to the tribes in the study area because they are engaged in sericulture for last 10 Year. The average annual income from the old occupation was Rs. 22050/-.

From 100 respondent 16 are take one crop in year while 81 are two, 03 are three. All respondent received dfls from sericulture department and they are satisfied with department. Primary host plant for silkworm rearing is in the priority of T.arjuna, T.tomentosa, M.alba and S.robusta with Z.zuzuba and that is 3360 for each respondent. All respondents accepted that the work of sericulture is comparatively better than other work.

\subsection{Cocoon Production and Profit}

It is estimated that an averages of 7500 numbers of cocoons are produced in each crop and an average of 5960/- Rs. are gain by respondent while average yearly production is 20400 numbers and income about 17820/Rs. respondents. 87 respondents getting losses some time in this occupation and the reasons are high temperature and humidity followed by diseases and pollution. Government did not give compensation for any crop loss (Dewangan, 2009).

\subsection{Sericulture and Social Impact}

All the respondents want to attach continue with sericulture because it is suited to their lifestyle. The work is simple and can be done without any cost. Sericulture can serve better for the additional income generation and lay concrete on the way for the local employment generation. All respondents have view that sericulture has not affected their traditional business, their economic status has changed and denied for any migration or displacement caused. The change in annual income is reported approx. double which is good in amount.

\section{CONCLUSION}

Sericulture is the source of additional income generation.

Sericulture provides more than 50\% employment to the respondent in a year thus stops the inter-state migration. According to the MNREGA (Mahatma Gandhi National Rural Employment Guaranty Act.) job card holder population must receive 100 days employment in a year where as sericulture provides 151200 days i.e., $63 \%$.

The average annual income from the old occupation were estimated as Rs. 22050/-. Due to this practices respondent were earned around double income than earlier income. This piece of micro level study has validated that the tribal's have been immensely benefited 
through additional income by adopting this profession as compared to their traditional occupation. Large production base, availability of skills, land and labor, silkworm breeds/hybrids, Established infrastructure, Low investment, short gestation period and higher returns, Easily adoptable technologies and strong domestic demand-pull are strengths of sericulture in study area. This occupation has stimulated habit of saving, microenterprise, reduction in seasonal out-migration; improvement in living conditions among a section of tribal families adopted this occupation. Sericulture is suited the life style of tribe because practice is simple and can be done without any cost and skill. Sericulture activities provide a perfect choice for the women because of the very nature of the activities that can take place close to the habitation. Women members get a steady source of income from tasar silkworm rearing during a period when no work is available in the neighborhood. Thus, the income from sericulture not only helped to maintain their family during lean agricultural season, but also ensures continuance of education to their children and boosted the morale of these tribal women through self-employment. Sericulture sector eminently qualifies as one of the most appropriate agro-based cottage industry for rural development, environment protection and rejuvenation. This sector is not only important for generating rural employment and preventing rural migration but also for role in protection and preservation of ecology, heritage and socio-cultural values.

\subsection{Suggestion}

- The government should give them compensations for the losses incurred in this occupation due to diseases and the negative impact of natural factors

- There should be enough loan facilities for the improvement of their occupation which is still more beneficial

- The government should be encouraging them to make clothes along with sericulture occupation

- Provision of refresher training programme for the silkworm rearers

- Focusing on use of new technology

\section{REFERENCES}

Ahmed, S.A. and R.K. Rajan, 2011. Exploration of Vanya silk biodiversity in north eastern region of India: Sustainable livelihood and poverty alleviation. Proceedings of the International Conference on Management, Economics and Social Sciences, (MESS’ 11), Bangkok, pp: 485-489.
Benchamin, K.V. and M.S. Jolly, 1987. Employment and income generation in the rural areas through sericulture. Indian Silk.

Brahmachari, B.N., 2004. Socio-economic Impacts of Tasar Rearers in Sundargrah Orissa. Annual Report CSTRI, Ranchi 2004.

Brahmachari, B.N., 2006. Socio-economic study of tasar silkworm Rearers, Reelers and Weavers in Chhattisgarh. Annual Report, CTR\&TI, Ranchi.

Chatterjee, K.K. and D. Chakravorty, 2009. Prospect of tasar cultivation in Chhattisgarh and role in rural development. Ethnoforestry: The Future of Indian Forestry, pp: 315-329.

Chatterjee, K.K., H. Chandra, R. Gupta and D. Chakravorty, 2007. Tasar culture-An approach of social upliftment of forest dwellers of Achanakmar Amarkantak Biosphere Reserve. Proceedings of Workshop Held at Tropical Forest Research Institute, Jabalpur on Research Needs for Achanakmar-Amarkantak Biosphere Reserve.

Dandin, S.B., 2008. Large scale farming sericulture: A field reality. Indian Silk, 46: 16-20.

Dewangan S.K., K.R. Sahu and K.V. Achari, 2011a. Sericulture: A tool of eco-system checking through tribal. J. Environ. Res. Dev., 6: 165-173.

Dewangan, S.K., 2009. Analytical study of Impact of sericulture on Tribal economy with special reference to Kharasia block of Raigarh dist. Life Sci. Bull., 6: 141-144.

Dewangan, S.K., K.R. Sahu, K.V. Achari and S. Soni, 2011b. Socio-Economic empowerment of tribal women through sericulture a study of lailunga block of Raigarh District, Chhattisgarh, India. Int. J. Bus. Manage., 6: 297-302.

DG, 2004. Sericulture in Chhattisgarh.

Ganie, N.A., A.S. Kamili, M.F. Baqual, R.K. Sharma and K.A. Dar et al., 2012. Indian sericulture industry with particular reference to Jammu and Kashmir. Int. J. Adv. Biol. Res., 2: 194-202.

Hansda, G., R.M. Reddy, M.K. Sinha, N.G. Ojha and N.B.V. Prakash, 2008. Ex-situ stabilization and utility prospects of "Jata" Ecorace of Tropical Tasar Silkworm Antheraea mylitta Drury. Int. J. Indus. Entomol., 17: 169-172.

Hanumappa, H.G., 1993. Economics issues in sericulture: A case study of Karnataka. Sericologia, 25: 209-217.

Jagannathan, N., 1995. Impacts of sericulture on income and employment generation. Indian Silk, 33: 11-16.

Jolly, M.S., 1967. A brief report on wild sericigeneous in india with special reference to tasar culture. World Meet Silk Product, Muricia, pp: 1-6. 
Kumaresan, P. and R.G.G. Devi, 2007. An economic analysis of large-scale farming in irrigated sericulture. Annual Report, CTR\&TI, Mysore.

Mahapatra, H.C., 2009. Tropical tasar biodiversity and forestry. Proceedings of the National workshop on Seri-Biodiversity Conserv, Mar. 7-8. CSGRC, CSB, Hosur, India, pp: 163-167.

Malik, M.S., P. Kaushal and R.B. Sah, 2008. Socioeconomic upliftment of tribal communities in Jharkhand through Agroforestry based farming system. Birsa Agril. University, Ranchi.

Nagaraju, J., 2008. Silk of India, grace and luster. Biotechnol. News, 3: 4-7.

Narsimha, M.L., 2003. Problems and Prospects of Sericulture. 1st Edn., Discovery Publishing House, New Delhi, ISBN-10: 8171416284, pp: 70.

Nayak, B.K., 2000. Biodiversity conservation of wild tasar silk moth Antheraea paphia L. of Simlipal Biosphere reserve and strategy for its economic utilization. Int. J. Wild Silk Moth, 5: 367-370.

Ojha, N.G., R.M. Reddy, G. Hansda and M.K. Sinha, 2009. Status and potential of Jata, a new race of Indian tropical tasar silkworm (Antheraea mylitta Drury). Acad. J. Entomol., 2: 80-84.

Rai, S., 2006. Tasar sericulture, an emerging discipline for conservation and sustainable utilization of natural resources. The Vision Review Point.

Rakesh, G., 2008. Tasar culture showed them the way. Indian Silk.

Ramalaxmi, C.S., 2007. Potential for participation of women in Sericulture sector.
Seidavi, A., A. Bizhannia, M. Mawajpour, Z. Mirhoseini and M. Ghanipoor, 2005. Investigation on necessity and methods of establishment of sericultural cooperatives. Sericologia, 46: 169-182.

Shetty, K.K., K. Sathyanarayana, J.N. John and I. Jose, 2007. Vanya silks of India-Exploring New Horizons.

Shrivastav, P.K., 2005. Sericulture activities provide a perfect choice for the women. Sericulture and seribiodiversity.

Singhvi, N.R., D.D. Sharma and R.K. Datta, 1996. Mulberry-a boon for social forestry. Ind. Silk, 35: 51-52.

Sinha, B.R.R.P., 2003. Forest policies and Tasarculture. Workshop held on April 10 at Dehradun.

Suryanarayana, N. and A.K. Shrivastava, 2005. Monograph on Tropical Tasar Silkworm. Central Tasar Research and Training Institute, Central Silk Board, Ranchi, India, pp: 1-87.

Thangavelu, K., 2002. Future research strategy for nonmulberry sericulture with particular reference to tasarculture: Advances in Indian sericulture research. Proceedings of the National Conference on Strategies for Sericulture Research and Development, Nov. 16-18, CSRTI, CSB, Mysore, India, pp: 365-368.

Thapa, R.B. and K.B. Shrestha, 1999. Silkworm rearing technology. Proceedings of the Workshop at Bhaktapur, Nepal, Dec. 21. 